\title{
Coronary artery disease in severe haemophilia
}

\author{
M SMALL, A S JACK, G D O LOWE, A F MUTCH, C D FORBES, C R M PRENTICE \\ From University Department of Medicine and the Department of Pathology, Royal Infirmary, Glasgow
}

SUMMARY It has been suggested that the coagulation defect in haemophilia A protects these patients from coronary artery disease. We report two patients with severe haemophilia, who each had severe atheroma localised to the coronary arteries. Both patients had received only small amounts of factor VIII concentrates in their lifetime because of various social reasons. In one case death resulted from myocardial infarction secondary to an occlusive thrombus in a coronary artery. The implications of these findings to the pathogenesis of vascular disease are discussed.

There is recent interest in the contribution of clotting factors including antihaemophilic factor (factor VIII coagulant activity=FVIII:C) to coronary artery disease $^{1}$ but little clinical information on coronary disease in patients with haemophilia $A$ is available. It would be valuable to see if the varying grades of severity of haemophilia had any influence on the development of coronary artery disease as this would provide further clinical evidence as to the importance of FVIII:C in its aetiology. We now report two patients with haemophilia who were middle aged, virtually untreated, and severely affected with pronounced coronary atheroma; in one of these patients death resulted from myocardial infarction caused by an occlusive coronary thrombosis.

\section{Case 1}

A 57 year old severe haemophiliac (FVIII:C $<1 \mathrm{U} / \mathrm{dl}$ ) was admitted with a three day history of abdominal discomfort and haematemesis. In the past he had experienced severe recurrent haemorrhagic problems but as he lived in the remote Outer Hebrides these episodes had been treated symptomatically without FVIII:C replacement. At the age of 40 , when first reviewed at the Regional Haemophilia Centre, he was totally crippled because of destructive arthropathy. Treatment for haemorrhagic episodes thereafter was given with fresh frozen plasma and then with cryoprecipitate and FVIII:C concentrates when these became available. In view of his severe flexion contractures and poor venous access replacement therapy was restricted to major haemorrhages. For example in

Accepted for publication 8 March 1983 the year preceding this episode he had received only 2000 U of FVIII:C concentrates for two episodes of joint haemorrhage. There was no history of hypertension or ischaemic heart disease but he had smoked over 30 cigarettes a day since he was a teenager.

On admission he had a further haematemesis for which he was given 2 units of blood and $2500 \mathrm{U}$ of FVIII:C concentrate $(31 \mathrm{U} / \mathrm{kg})$. The electrocardiogram and chest $x$-ray film were normal. The next day he was improved: haemoglobin was $12.7 \mathrm{~g} / \mathrm{dl}$ and no inhibitor to FVIII:C was detected. A total of $4000 \mathrm{U}$ of concentrates were given (peak FVIII:C level 88 $\mathrm{U} / \mathrm{dl})$, and he was started on tranexamic acid ( $1 \mathrm{~g}$, thrice daily), to inhibit gastric fibrinolytic activity, cimetidine in standard dosage, and he was transfused a further 3 units of blood. Next morning his haemoglobin was $14 \mathrm{~g} / \mathrm{dl}$ and he was haemodynamically stable. Ten hours later, however, he became severely dyspnoeic and complained of central chest pain. Pulse was $140 / \mathrm{min}$, blood pressure $150 / 90 \mathrm{mmHg}$, and there was widespread bronchospasm. Soon after he had a cardiac arrest, and died despite attempts at resuscitation.

At necropsy a thrombotic occlusion of the right coronary artery was present, together with severe atheroma of the other coronary arteries (Fig. 1). The heart weighed $450 \mathrm{~g}$, with evidence of left ventricular hypertrophy. An old anterior myocardial infarction was present. Histology of the inferior myocardium showed changes of early infarction. Other findings included micronodular cirrhosis and acute gastritis which had been the cause of the haematemesis. The clinical and pathological findings suggest that the cause of death was acute inferior myocardial infarction secondary to a right coronary artery occlusion. 


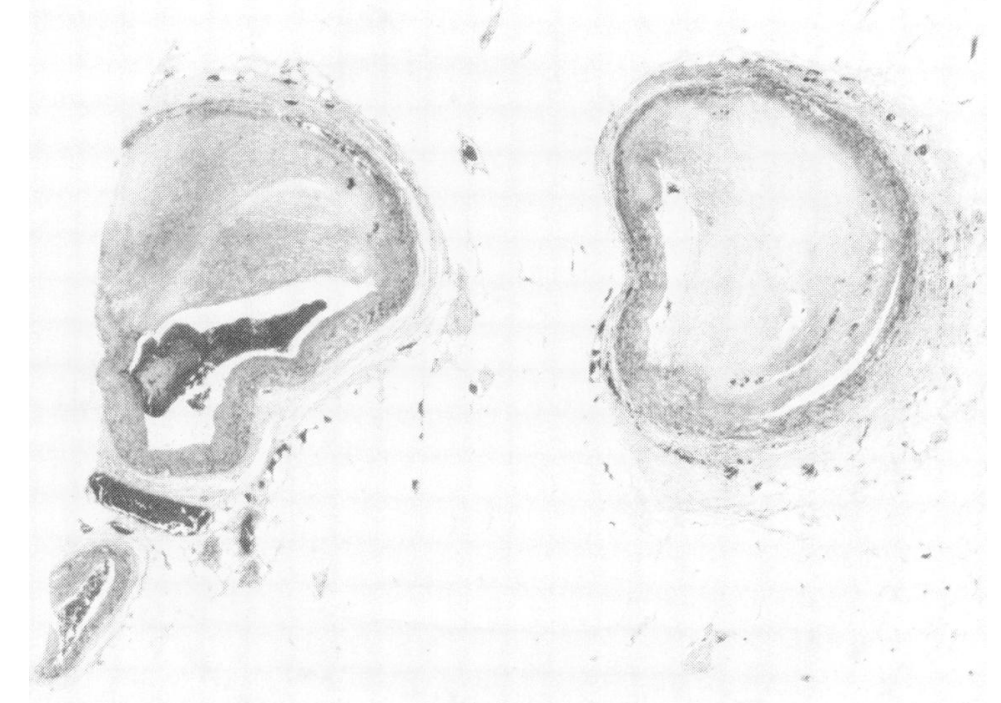

Fig. 1 Cross-section through branches of left anterior descending coronary artery showing severe atheroma.

\section{Case 2}

A 53 year old severe haemophiliac (FVIII:C $<1 \mathrm{U} / \mathrm{dl}$ ) was admitted with a five day history of abdominal pain and found to have peritonitis, free air in the abdominal cavity, and septicaemia.

As a child he had lived in a remote West Highland town where treatment with plasma products was non-existent. He had suffered frequent joint haemorrhages causing pronounced arthropathy with flexion contractures of both knees and elbows. As he got older the joint haemarthroses became less frequent. He first received cryoprecipitate at the age of 38 and FVIII:C replacement was only administered on a few occasions in his life when he required hospital admission. Some years he received no factor concentrates at all but in the year before this event he had been given $7000 \mathrm{U}$ of concentrate during two separate hospital admissions for intramural bowel wall haematoma. He was a non-smoker and had no electrocardiographic or clinical evidence of ischaemic heart disease.

At operation he was found to have a perforated sigmoid diverticulum and underwent a defunctioning colostomy. Despite full haemostatic cover, antibiotics, and inotropic support he died five days after the operation.

At necropsy there was almost complete atheromatous occlusion of the left anterior descending coronary artery (Fig. 2) and patchy lesions in the other main coronary vessels. There was no evidence of myocar- dial infarction. Minimal atheroma was present in the other parts of the arterial tree. The cause of death was generalised sepsis.

\section{Discussion}

While much of the interest in the pathogenesis of atheroma has focused on lipid deposition ${ }^{2}$ there is considerable evidence to show that thrombosis also plays an important role. ${ }^{3}$ Patients with severe haemophilia these days will receive about 40000 units of FVIII:C concentrates per year. In comparison, our two severely affected patients received much smaller quantities of factor concentrate in their lifetime and none until the ages of 38 and 40 , despite which severe coronary atheroma had developed. Development of atheroma in a haemophiliac therefore suggests that FVIII:C is not essential for the production of the lesion and may be the result of arterial injury releasing tissue thromboplastin which activates thrombin and fibrin formation without requirement of FVIII:C. ${ }^{4}$ It is also possible that the more important process during the formation of an atheromatous plaque is a platelet mediated effect on the vessel wall. A number of experimental studies support this view both in vivo $^{5}$ and in culture systems employing smooth muscle cells. ${ }^{6}$ Platelet function in haemophilia is normal because of the normal content of FVIII related antigen in this disorder.

In our two patients the coronary arteries were 


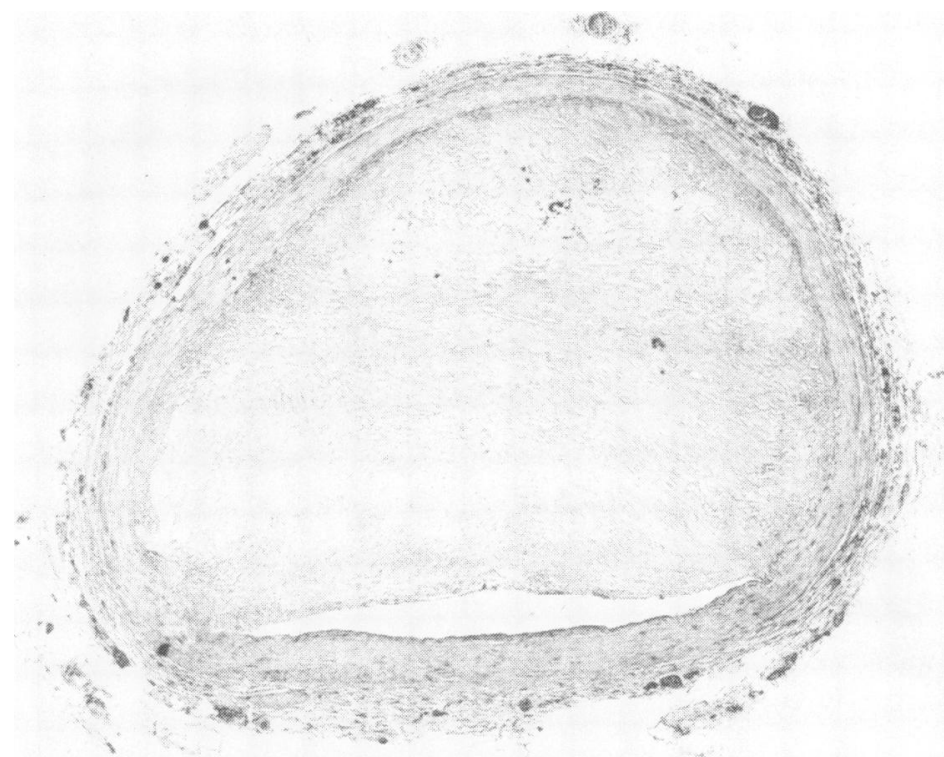

Fig. 2 Cross-section through lefi anterior descending artery almost completely occluded by atheroma.

severely atheromatous, and other vessels were relatively less affected. It may be that FVIII:C could potentiate atherogenesis so that in haemophilia atheroma develops only in areas of high intrinsic susceptibility. Variation in the tendency of arteries to form atheroma has been suggested as having a genetic $^{7}$ or a mechanical basis. ${ }^{8}$ This is a hypothesis which could be tested if more postmortem data from haemophiliacs became available and such a formal systematic study is being set up by the UK Haemophilia Reference Centre Directors.

In a current study of mortality in haemophilia in the UK no case of fatal myocardial infarction has yet been noted (C D Forbes, 1982, unpublished observations) and indeed only two cases of myocardial infarction in classic haemophilia have been previously reported. 910 Both these subjects were over 68 years of age and only mildly affected with haemophilia. There are three possible reasons for the low incidence of myocardial infarction in haemophilia. Firstly, the low incidence may be more apparent than real, since haemophilia is rare, and many patients with severe haemophilia died at a young age before replacement treatment became available. Secondly, patients with severe haemophilia may have a reduced tendency to form occlusive thrombi in atheromatous vessels. This would be consistent with the observations from a secondary prevention study in which interference with fibrin formation by oral anticoagulants, in elderly patients, reduced the incidence of cardiovascular death. ${ }^{11}$ Thirdly, they may form less atheroma.

Although pronounced atheroma has been noted before in haemophilia, ${ }^{12} 13$ in no reported case has a coronary artery thrombus been detected at necropsy. As occlusion of a coronary artery by thrombus is usually found in the majority of cases of transmural myocardial infarction, 1415 this may explain the rarity of myocardial infarction despite atheroma in these patients. While frequent replacement with factor concentrates over a prolonged period could be important in atheroma production, even one treatment episode could predispose to acute thrombosis. In our first case therefore it is possible that the replacement treatment which the patient received to prevent further gastrointestinal haemorrhage may have contributed to the formation of an occlusive thrombus. Factor concentrates also contain significant proportions of $\tilde{O}$ fibrinogen which could also be potentially throm- N bogenic. The administration of the fibrinolytic $\sigma$ inhibitor, tranexamic acid, might also be implicated.

Treatment of haemophiliacs with FVIII:C replacement is now widely available and it is unlikely that cases, such as the two described, of virtually 0 untreated severe haemophilia will be seen again. If the low incidence of myocardial infarction in haemophilia is the result of failure to form occlusive thrombi in atheromatous arteries, then it will be important to see if the alteration in management of these patients will 
affect the incidence of cardiovascular disease.

High FVIII:C levels have been shown prospectively to be a positive risk association in men who die from cardiovascular disease. ${ }^{1}$ The two cases presented do not detract from the potential importance of increased clotting factors in the aetiology of coronary artery disease and we do not wish to imply that the occurrence of coronary artery disease in patients with haemophilia necessarily means there is no general association between FVIII:C levels and coronary artery disease. Our two cases, however, do illustrate the complexity of the subject and indicate the value of continued study of patients with hereditary coagulation abnormalities, as well as epidemiological studies of clotting factors in populations.

\section{References}

1 Meade TW, North WRS, Chakrabarti R, et al. Haemostatic function and cardiovascular death: early reports of a prospective study. Lancet 1980; i: 1050-4.

2 Smith EB. Relationship between lipids and atherosclerosis. In: Bloom AL, Thomas DP, eds. Haemostasis and thrombosis. London: Churchill Livingstone, 1981: 554-74.

3 Woolf $\mathrm{N}$. Thrombosis and atherosclerosis. In: Bloom AL, Thomas DP, eds. Haemostasis and thrombosis. London: Churchill Livingstone, 1981: 527-53.

4 Astrup T. Haemophilia and cardiovascular disease. In: Brinkhous KM, Hemker HC, eds. Handbook of haemophilia. Part I. Amsterdam: Excerpta Medica, 1975: 287-99.
5 Woolf N, Carstairs KC. Infiltration and thrombosis in atherogenesis—a study using immunofluorescent techniques. Am f Pathol 1967; 51: 373-86.

6 Rutherford RB, Ross R. Platelet factors stimulate fibroblasts and smooth muscle cells quiescent in plasma serum to proliferate. F Cell Biol 1976; 69: 196-203.

7 Holmes DR Jr, Kennel AJ, Smith HC, Gordon H, Moore SB. Coronary artery disease in twins. Br Heart $\mathcal{f}$ 1981; 45: 193-7.

8 Ross R, Glomset JA. The pathogenesis of atherosclerosis. Part 2. N Engl F Med 1976; 295: 420-5.

9 Borchgrevink CF. Myocardial infarction in a haemophiliac. Lancet 1959; i: 1229-30.

10 Boivin JM. Infarctus du myocarde chez un hémophile. Arch Mal Coeur 1954; 47: 351-4.

11 Sixty Plus Reinfarction Study Group. A double blind trial to assess long-term anticoagulant therapy in elderly patients after myocardial infarction. Lancet 1980; ii: 989-93.

12 Stewart JW, Acheson ED. Atherosclerosis in a haemophiliac. Lancet 1957; i: 1121-2.

13 Kim HC, Lacy C, Shea S, Saidi P. Haemostatic factors and coronary heart disease [Letter]. Lancet 1981; i: 1267.

14 Davies MJ, Woolf N, Robertson WB. Pathology of acute myocardial infarction with particular reference to occlusive coronary thrombi. Br Heart f 1976; 38: 659-64.

15 DeWood MA, Spores J, Notske R, et al. Prevalence of total coronary occlusion during the early hours of transmural myocardial infarction. $N$ Engl f Med 1980; 303: 897-902.

Requests for reprints to $\operatorname{Dr} M$ Small, University Department of Medicine, Royal Infirmary, Glasgow G4 OSF. 